\title{
Limitations of mammography in the diagnosis of breast diseases compared with ultrasonography: a single-center retrospective analysis of 274 cases
}

Hong Zhao ${ }^{1 \dagger}$, Liwei Zou ${ }^{1 \dagger}$, Xiaoping Geng ${ }^{2^{*}}$ and Suisheng Zheng ${ }^{1}$

\begin{abstract}
Background: The aim of this study is to compare X-ray mammography (MG) and ultrasonography (US) in the diagnosis of breast diseases in Chinese women.

Methods: We retrospectively analyzed X-ray mammograms of 274 patients with US and surgical/pathological results of breast diseases diagnosed at The Second Affiliated Hospital of Anhui Medical University (Hefei, China) between March 2011 and November 2014. The MG and US data were compared to surgical records using the results from post-surgical pathological examinations as the gold standard.

Results: The overall sensitivity, specificity, accuracy, false-positive, false-negative, positive predictive value, and negative predictive value for the detection of breast cancer were $88.5 \%, 57.9 \%, 73.7 \%, 42.1 \%, 11.5 \%, 69.2 \%$, and $82.5 \%$, respectively, for MG and 95.9\%, 66.7\%, 81.8\%, 33.3\%, 4.1\%, 75.5\%, and 93.8\%, respectively, for US. Of the 274 cases, lesion size by MG agreed with surgery in $133(48.5 \%)$ patients compared with $216(78.8 \%)$ by US $(P<0.01)$. Lesion location by MG agreed with surgery in 146 (53.3\%) patients compared with 257 (93.8\%) by US $(P<0.01)$. These values were then stratified according to age, menstrual status, breast density, and breast volume, and the agreement rates of MG with surgery were lower than that of US (all $P<0.01)$, except when the lesion size was $>5 \mathrm{~cm}(P>0.05)$.

Conclusions: US was better than MG in the preoperative evaluation of breast diseases of Chinese women. These results suggest that US could be more useful for detecting breast lesions in China, especially for younger women with dense breasts.
\end{abstract}

Keywords: Breast disease, Mammography, Ultrasound, Breast cancer, Surgery

\section{Background}

Breast diseases, both benign and malignant, affect many women worldwide. To enhance early detection, women are encouraged to undergo routine screening by mammography (MG) [1]. Breast density represents the proportion of different tissue types within a woman's breast. Specifically, breast and connective tissues are denser than fat, and this difference is apparent by MG. When breast density is high (that is, when there is a greater amount of breast and connective tissues compared with fat), mammograms are more difficult to interpret because a lesion may be shadowed by the dense tissues.

\footnotetext{
*Correspondence: 178331090@qq.com

${ }^{\dagger}$ Equal contributors

${ }^{2}$ Department of Surgery, The Second Affiliated Hospital of Anhui Medical University, 678 Furong Road, Hefei, Anhui 230000, China

Full list of author information is available at the end of the article
}

Moreover, research has shown that women with high breast density are at increased risk of developing breast cancer [2]. Breast density varies by race, and many Chinese women have dense- or intermediate mixedtype breast density [3]. Thus, MG may fail to accurately identify tumors within this population. In some countries, doctors have begun to implement alternative methods for women with dense breasts. Such measures include the use of ultrasonography (US) and magnetic resonance imaging (MRI) [4,5]. MRI is a useful tool to assess breast diseases and has been shown to have a higher sensitivity than MG $[4,5]$. However, MRI is expensive and waiting lists are often long, limiting its use in underdeveloped areas of China. In contrast, US might be more accurate than MG and is cheaper than 
MRI for the preoperative evaluation of breast diseases in women $[4,5]$.

Therefore, the present study aimed to retrospectively analyze MG and US of 274 patients with surgical pathologyconfirmed breast diseases in the diagnosis of breast diseases in Chinese women, to compare the diagnosis value of MG and US, and to establish an optimal modality of breast diseases in underdeveloped areas of China.

The results of the present study could identify the limitations of MG in the diagnosis of breast diseases in Chinese women, especially in those with high-density and relatively small breasts.

\section{Methods}

\section{Patients}

Two hundred seventy-four consecutive female patients diagnosed with breast diseases and who underwent surgery at The Second Affiliated Hospital of Anhui Medical University (Hefei, China) from March 2011 through November 2014 were included in the present study. Inclusion criteria were as follows: 1) presence of a breast lesion on imagery; 2) the lesion underwent surgery; 3) underwent preoperative MG and US before; 4) and lesion was confirmed by postoperative pathology. Women were excluded if they had undergone only MG or US. This retrospective study was approved by the Institutional Review Board of The Second Affiliated Hospital of Anhui Medical University. The need for individual consent was waived by the committee because of the retrospective nature of the study.

\section{MG and US assessment}

MG and US were both performed 2 weeks before surgery. Mediolateral oblique and craniocaudal digital MG of the breast were performed using a molybdenum-rhodium target full-field digital MG system (Senographe 2000D, General Electric, Pittsburgh, PA, USA). If required, additional MG views were obtained. An automatic exposure factor was used, and adequate pressure was applied on the breast. All MG examinations were read by two radiologists who were blinded to the patient's identity and medical background. The imaging interpretation was based on the American College of Radiology (ACR) BIRADS (Breast Imaging Reporting and Data System) lexicon [6]. Breast lesions were classified into six categories according to the lesion margin and calcification status: BI-RADS $0=$ unsatisfactory MG, and additional imaging evaluations are needed; BI-RADS $1=$ negative, no abnormality on MG; BI-RADS 2 = benign findings, presence of definite benign lesions without any signs of malignancy; BI-RADS 3 = probably benign lesions, including uncalcified lump with negative palpation and clear boundary and focal, asymmetric, clustering, round or dot-like calcifications, and a follow-up in a short time frame is suggested; BI-RADS $4=$ suspicious abnormality without typical signs of malignancy, including palpable, solid lumps with some clear margins, palpable complex cysts, palpable abscess, solid mass with irregular shape and infiltrating margin, and newly emerging clustered, tiny, polygonal calcifications, and biopsy should be considered; BI-RADS category $5=$ highly suggestive of malignancy and appropriate actions should be taken. The total breast density was classified into ACR levels 1 to 4 [2]: level 1 , almost entirely fatty; level 2 , scattered fibroglandular densities; level 3, heterogeneously dense; and level 4, extremely dense. In the present study, density levels 1 to 2 were defined as low density, and levels 3 to 4 were defined as high density. The volume of the breast was measured using the formula proposed by Kalbhen et al. [7,8]: breast volume $=\pi / 4 \times(W \times H \times C)$, where $W$ is the breast width, $H$ is the breast height, and $C$ is the compression thickness in craniocaudal MG.

US examination was performed using a color Doppler US device (PHLIPS iu22, Philips, Best, The Netherlands) with a probe frequency of 10 to $18 \mathrm{~Hz}$. All US examinations were performed with the patient in the supine position for the medial parts of the breast and in the contralateral posterior oblique position with arms raised for the lateral parts of the breast. The US examinations were performed by board-certified radiographers classified by the ACR BI-RADS US standard.

The location and size of the lesions detected by MG and US were recorded. Lesion location was classified as located in the upper outer quadrant of the breast, the lower outer quadrant, the upper inner quadrant, the lower inner quadrant, the breast areola region, or the axillary tail region. Lesion size was classified as $\leq 2.0 \mathrm{~cm}, 2.1$ to $5.0 \mathrm{~cm}$, or $>5.0 \mathrm{~cm}$.

\section{Surgery}

All included patients underwent surgery. The location and size of the lesions were recorded during the surgery according to the same standard as MG and US. Pathology results were collected.

\section{Data collection}

Data were collected including BI-RADS category, microcalcifications, menstrual status, histopathology, lesion size, breast density, and breast volume. For the purpose of the present study, BI-RADS MG and US categories 1, 2, and 3 were considered as negative, and categories 4 and 5 were considered as positive.

\section{Statistical analysis}

SPSS 16.0 (SPSS Inc., Chicago, IL, USA) was used for statistical analysis. The breast cancer sensitivity, specificity, accuracy, false-positive, false-negative, positive predictive value, and negative predictive value were calculated. Histopathological examination was considered as the gold 
standard. A true negative was defined as negative benign lesion by histopathology. A true positive was defined as positive evidence of malignancy on histopathology. BI-RADS categories of 0 were excluded from sensitivity, specificity, accuracy, false-positive, false-negative, positive predictive value, and negative predictive value analysis but were kept for the analysis of the location agreement. Lesion size and location were compared between imaging modalities and surgery.

\section{Results}

\section{Characteristics of the patients}

Of the 274 patients, 132 were with pathologically proven malignancy and 142 were benign. Among these patients, 185 (67.5\%) were premenopausal and 89 (32.5\%) were postmenopausal. Patients aged from 24 to 80 years, with 129 (47.1\%) being $\leq 45$ years old and $145(52.9 \%)$ being $>45$ years old. The clinical data are shown in Table 1.

\section{Comparison between MG and US assessment}

As shown in Table 1, 41 (15.0\%) cases were classified as ACR level 1; 92 (33.6\%) were level 2; 127 (46.3\%) were level 3; and 14 (5.1\%) were level 4 . The average breast volume of the 274 cases was $419 \pm 149 \mathrm{ml}$ (range 91 to $1,130 \mathrm{ml}$ ), among whom $120(43.8 \%)$ were $\leq 400 \mathrm{ml}, 142$ (51.8\%) were 400 to $800 \mathrm{ml}$, and $12(4.4 \%)$ were $>800 \mathrm{ml}$.

Of the 274 cases, MG BI-RADS category was 0 in 38 (13.9\%) cases, category 1 in $30(10.9 \%)$, category 2 in 7 (2.6\%), category 3 in 43 (15.7\%), category 4 in 113 (41.2\%), and category 5 in 43 (15.7\%). US BI-RADS category was 1 in $4(1.5 \%)$ cases, category 2 in $32(11.7 \%)$, category 3 in $67(24.5 \%)$, category 4 in $150(54.7 \%)$, and category 5 in 21 (7.7\%) (Table 2).

\section{Comparison of the diagnostic accuracy between MG and US}

The overall sensitivity, specificity, accuracy, false-positive, false-negative, positive predictive value, and negative predictive value for the detection of breast cancer were $88.5 \%, 57.9 \%$, 73.7\%, 42.1\%, $11.5 \%$, 69.2\%, and $82.5 \%$, respectively, for MG and 95.9\%, 66.7\%, 81.8\%, 33.3\%, $4.1 \%, 75.5 \%$, and $93.8 \%$, respectively, for US. The overall values of US were higher than that of MG. These values were then stratified according to age, menstrual status, breast density, and breast volume (Table 3). Subgroups analyses presented in Table 3 also suggest that sensitivity and accuracy were lower with MG than with US in women $\leq 45$ years old (sensitivity: $73.7 \%$ vs. $89.5 \%$, accuracy: $65.4 \%$ vs. $76.0 \%$ ), premenopausal (sensitivity: $81.0 \%$ vs. $91.9 \%$, accuracy: $64.9 \%$ vs. $79.7 \%$ ), or with high breast density (sensitivity: 63.2\% vs. 92.3\%, accuracy: $71.7 \%$ vs. $79.7 \%$ ). We excluded 38 (14\%) patients who were classified as BI-RADS category 0 in MG because the imaging findings were unsatisfactory
Table 1 Patients' characteristics

\begin{tabular}{|c|c|}
\hline Characteristics & $N(\%)$ \\
\hline \multicolumn{2}{|l|}{ Age } \\
\hline$\leq 45$ & $129(47.1)$ \\
\hline$>45$ & $145(52.9)$ \\
\hline \multicolumn{2}{|l|}{ Menstrual status } \\
\hline Premenopausal & $185(67.5)$ \\
\hline Postmenopausal & $89(32.5)$ \\
\hline \multicolumn{2}{|l|}{ Pathology } \\
\hline IDC & $120(43.8)$ \\
\hline DCIS & $7(2.6)$ \\
\hline Fibroadenoma & $47(17.2)$ \\
\hline Papilloma & $9(3.3)$ \\
\hline Adenosis & $50(18.2)$ \\
\hline Inflammation & $14(5)$ \\
\hline Lipomyma & $7(2.6)$ \\
\hline Cyst & $8(2.9)$ \\
\hline Others (malignant) & $5(1.8)$ \\
\hline Others (benign) & $7(2.6)$ \\
\hline \multicolumn{2}{|l|}{ Lesion size (cm) } \\
\hline$\leq 2$ & $122(44.5)$ \\
\hline 2.1 to 5 & $135(49.3)$ \\
\hline$>5$ & $17(6.2)$ \\
\hline \multicolumn{2}{|l|}{ Breast Density } \\
\hline ACR1 & $41(15)$ \\
\hline ACR2 & $92(33.6)$ \\
\hline ACR3 & $127(46.3)$ \\
\hline ACR4 & $14(5.1)$ \\
\hline \multicolumn{2}{|l|}{ Breast Volume (ml) } \\
\hline$\leq 400$ & $120(43.8)$ \\
\hline 400 to 800 & $142(51.8)$ \\
\hline$>800$ & $12(4.4)$ \\
\hline
\end{tabular}

ACR. American College of Radiology; DCIS, ductal carcinoma in situ; IDC, invasive ductal carcinoma.

Table 2 BI-RADS categories in mammography and ultrasonography

\begin{tabular}{lll}
\hline BI-RADS & MG & US \\
\hline 0 & $38(13.9 \%)$ & $0(0 \%)$ \\
1 & $30(10.9 \%)$ & $4(1.5 \%)$ \\
2 & $7(2.6 \%)$ & $32(11.7 \%)$ \\
3 & $43(15.7 \%)$ & $67(24.5 \%)$ \\
4 & $113(41.2 \%)$ & $150(54.7 \%)$ \\
5 & $43(15.7 \%)$ & $21(7.7 \%)$ \\
Total & $274(100 \%)$ & $274(100 \%)$ \\
\hline
\end{tabular}

BI-RADS, Breast Imaging Reporting and Data System; MG, mammography; US, ultrasonography. 
Table 3 Comparison of diagnostic value between MG and US

\begin{tabular}{|c|c|c|c|c|c|c|c|c|}
\hline & Method & Sensitivity & Specificity & Accuracy & False-positive & False-negative & Positive PV & Negative PV \\
\hline \multirow[t]{2}{*}{ All } & MG & $88.5 \%$ & $57.9 \%$ & $73.7 \%$ & $42.1 \%$ & $11.5 \%$ & $69.2 \%$ & $82.5 \%$ \\
\hline & US & $95.9 \%$ & $66.7 \%$ & $81.8 \%$ & $33.3 \%$ & $4.1 \%$ & $75.5 \%$ & $93.8 \%$ \\
\hline \multirow[t]{2}{*}{ Age $\leq 45$ years } & MG & $73.7 \%$ & $60.6 \%$ & $65.4 \%$ & $39.4 \%$ & $26.3 \%$ & $51.9 \%$ & $80.0 \%$ \\
\hline & US & $89.5 \%$ & $68.2 \%$ & $76.0 \%$ & $31.8 \%$ & $10.5 \%$ & $61.8 \%$ & $91.8 \%$ \\
\hline \multirow[t]{2}{*}{ Age $>45$ years } & MG & $95.2 \%$ & $54.2 \%$ & $80.3 \%$ & $45.8 \%$ & $4.8 \%$ & $78.4 \%$ & $86.7 \%$ \\
\hline & US & $98.8 \%$ & $64.6 \%$ & $86.4 \%$ & $35.4 \%$ & $1.2 \%$ & $83.0 \%$ & $96.9 \%$ \\
\hline \multirow[t]{2}{*}{ Premenopausal } & MG & $81.0 \%$ & $53.8 \%$ & $64.9 \%$ & $46.2 \%$ & $19.0 \%$ & $54.8 \%$ & $80.3 \%$ \\
\hline & US & $91.9 \%$ & $71.4 \%$ & $79.7 \%$ & $28.6 \%$ & $8.1 \%$ & $68.7 \%$ & $92.9 \%$ \\
\hline \multirow[t]{2}{*}{ Postmenopausal } & MG & $96.6 \%$ & $73.9 \%$ & $90.2 \%$ & $26.1 \%$ & $3.4 \%$ & $90.5 \%$ & $89.5 \%$ \\
\hline & US & $100.0 \%$ & $47.8 \%$ & $85.4 \%$ & $52.2 \%$ & $0.0 \%$ & $83.1 \%$ & $100.0 \%$ \\
\hline \multirow[t]{2}{*}{ Low breast density } & MG & $92.9 \%$ & $52.1 \%$ & $76.3 \%$ & $47.9 \%$ & $7.1 \%$ & $73.9 \%$ & $83.3 \%$ \\
\hline & US & $98.6 \%$ & $62.5 \%$ & $83.9 \%$ & $37.5 \%$ & $1.4 \%$ & $79.3 \%$ & $96.8 \%$ \\
\hline \multirow[t]{2}{*}{ High breast density } & MG & $63.2 \%$ & $82.7 \%$ & $71.7 \%$ & $17.3 \%$ & $36.8 \%$ & $82.7 \%$ & $63.2 \%$ \\
\hline & US & $92.3 \%$ & $69.7 \%$ & $79.7 \%$ & $30.3 \%$ & $7.7 \%$ & $70.6 \%$ & $92.0 \%$ \\
\hline
\end{tabular}

MG, mammography; PV, predictive value; US, ultrasonography.

to detect the lesions. Among them, 7 cases were invasive ductal carcinoma (IDC). Thirty (10.9\%) cases with MG BI-RADS category 1 underwent surgery because of the presence of an obvious mass by US or clinical examination. Among these 30 patients, histopathology results revealed the presence of 9 cancers and 21 benign lesions. Figure 1 shows a typical example of the missed diagnosis of breast disease by MG.

\section{Comparison of agreement rate with surgery between MG and US}

Of the 274 cases, lesion size by MG agreed with surgery in $131(47.8 \%)$ patients compared with 217 (79.2\%) by US. Of the 274 cases, lesion location by MG agreed with surgery in 128 (46.7\%) patients compared with 250 (91.2\%) by US. These values were then stratified according to age, menstrual status, breast density, and breast volume (Table 4), and the agreement rates of MG with surgery were lower than that of US (all $P<0.01$ ), except when the lesion size was $>5 \mathrm{~cm}(P>0.05)$ (Table 4$)$. As shown in Figures 2 and 3, MG often failed to identify the size and location of the lesion due to dense glands and overlapping structures.

The chi-square test was used for agreement rates for lesion size and location between MG and US. $P$ values $<0.05$ were considered as significant.

\section{Discussion}

The aim of the present study was to compare X-ray MG and US in the diagnosis of breast diseases in Chinese women. Results showed that the overall sensitivity, specificity, accuracy, false-positive, false-negative. positive predictive value, and negative predictive value were significantly higher with US than with MG. Subgroups analyses suggested that sensitivity and accuracy were lower with MG than with US in women $\leq 45$ years old, premenopausal,

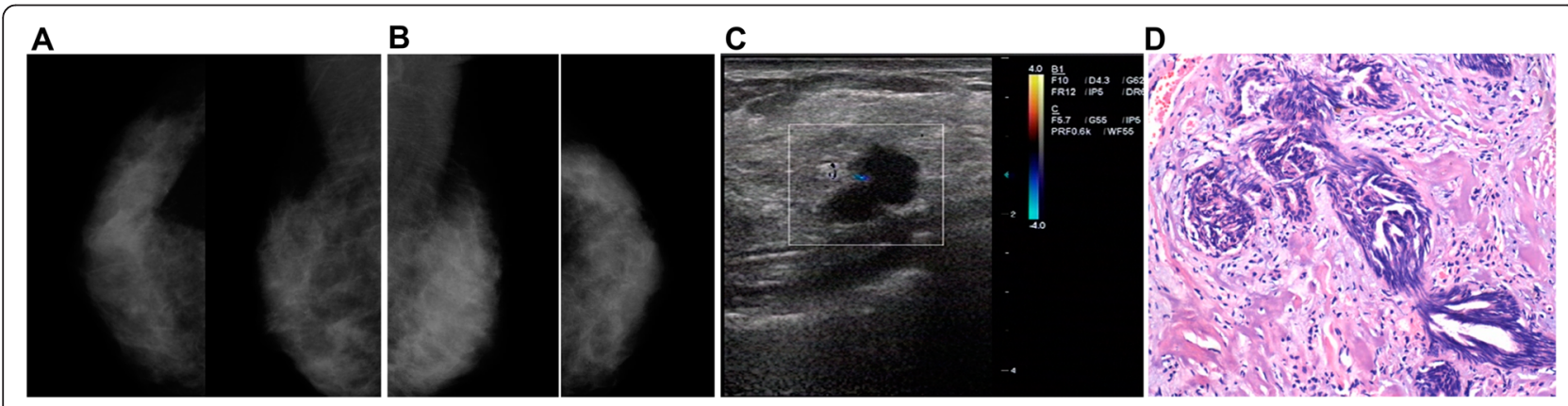

Figure 1 MG, US, and post-surgical pathology results from a 43-year-old patient with a lump in her right breast. (A) Craniocaudal and mediolateral oblique views of the molybdenum target MG of the right breast. MG were unsatisfactory (BI-RADS category 0 ) because of the dense gland structure. (B) MG of the left breast of the same patient. (C) US detected an irregular hypoechoic lesion with clear boundaries. (D) Intra-operative pathology revealed an invasive ductal carcinoma (HE staining, $\times 100$ ). This is a typical example of a missed diagnosis of breast disease by MG. 
Table 4 Comparison between MG and US for agreement rates for lesion size and location

\begin{tabular}{|c|c|c|c|c|c|c|}
\hline \multirow[t]{2}{*}{ Variable } & \multicolumn{2}{|l|}{ Lesion size } & \multirow[b]{2}{*}{$P$ value } & \multicolumn{2}{|l|}{ Lesion location } & \multirow[b]{2}{*}{$P$ value } \\
\hline & MG & US & & MG & US & \\
\hline All & 131/274 (47.8\%) & $217 / 274(79.2 \%)$ & $<0.001$ & $128 / 274(46.7 \%)$ & $250 / 274(91.2 \%)$ & $<0.001$ \\
\hline Age $\leq 45$ & $55 / 129(42.6 \%)$ & $100 / 129(77.5 \%)$ & $<0.001$ & $52 / 129(40.3 \%)$ & 116/129 (89.9\%) & $<0.001$ \\
\hline Age $>45$ & 76/145 (52.4\%) & $117 / 145$ (80.7\%) & $<0.001$ & $76 / 145$ (52.4\%) & 134/145 (92.4\%) & $<0.001$ \\
\hline Premenopausal & $82 / 185$ (44.3\%) & 144/185 (77.8\%) & $<0.001$ & 81/185 (43.8\%) & 167/185 (90.3\%) & $<0.001$ \\
\hline Postmenopausal & 49/89 (55.1\%) & 73/89 (82\%) & $<0.001$ & 47/89 (52.8\%) & 83/89 (93.3\%) & $<0.001$ \\
\hline Low breast density & 74/133 (55.6\%) & 109/133 (82.0\%) & $<0.001$ & 67/133 (50.4\%) & 123/133 (92.5\%) & $<0.001$ \\
\hline High breast density & $57 / 141(40.4 \%)$ & 108/141 (76.6\%) & $<0.001$ & $61 / 141(43.3 \%)$ & 127/141 (90.1\%) & $<0.001$ \\
\hline Lesion $<2 \mathrm{~cm}$ & 46/122 (37.7\%) & 102/122 (83.6\%) & $<0.001$ & 43/122 (35.2\%) & 111/122 (91.0\%) & $<0.001$ \\
\hline Lesion 2.1 to $5 \mathrm{~cm}$ & 79/135 (58.5\%) & 108/135 (80.0\%) & $<0.001$ & 74/135 (54.8\%) & 123/135 (91.1\%) & $<0.001$ \\
\hline Lesion $>5 \mathrm{~cm}$ & 6/17 (35.3\%) & 7/17 (41.2\%) & 0.724 & $11 / 17$ (64.7\%) & 16/17 (94.1\%) & 0.09 \\
\hline
\end{tabular}

MG, mammography; US, ultrasonography.

or with high breast density. Compared with the surgical data, the agreement rates for lesion size and location of MG were lower than that of US (all $P<0.01$ ), except when the lesion size was $>5 \mathrm{~cm}(P>0.05)$. These results suggest that US could be a better breast imaging modality for Chinese women.

Assessment of breast diseases with imaging modalities such as MG and US provides a mean for lesion detection and diagnosis. In western countries, MG is the primary breast cancer screening tool and has demonstrated evidences of reduction of breast cancer mortality [9-11]. However, compared with women from western countries, Chinese women have their unique characteristics such as high breast density and small breast volume that influence the sensitivity and accuracy of MG in detecting breast diseases [12]. Breast density is negatively associated with MG sensitivity [13], as well as with mortality from breast cancer [14]. Indeed, the intrinsic limitations of MG result in failure to detect $10 \%$ to $15 \%$ of breast cancers, and MG sensitivity is reduced particularly in women with dense breast tissue [1], as shown in the present study. These data suggest that MG might not be an optimal choice for detecting breast lesions in Chinese women $[15,16]$, which is supported by a study performed in American women with dense breasts $[17,18]$.

In the present study, all patients were from the Anhui Province, which is an undeveloped province in the middle of China, and most of these patients had dense breast tissue and small breast volume. Of the 274 cases, 38 $(13.9 \%)$ were classified as BI-RADS category 0 , meaning that an important proportion of women undergoing MG could not be satisfactorily assessed, which is supported by previous studies [19,20]. In addition, $30(10.9 \%)$ patients assessed as being BI-RADS category 1 by MG had a palpable mass by clinical examination or had an obvious mass by US, prompting surgery. Among these 30 patients, nine were diagnosed with cancer. Therefore, these results suggest that even MG BI-RADS category 1 was not accurate enough and may miss some malignant lesions.

In the present study, MG had significantly lower sensitivity, specificity, accuracy, false-positive, false-negative, positive predictive value, and negative predictive value than US. Stratified analysis showed that young age, premenopausal, and high breast density decreased the

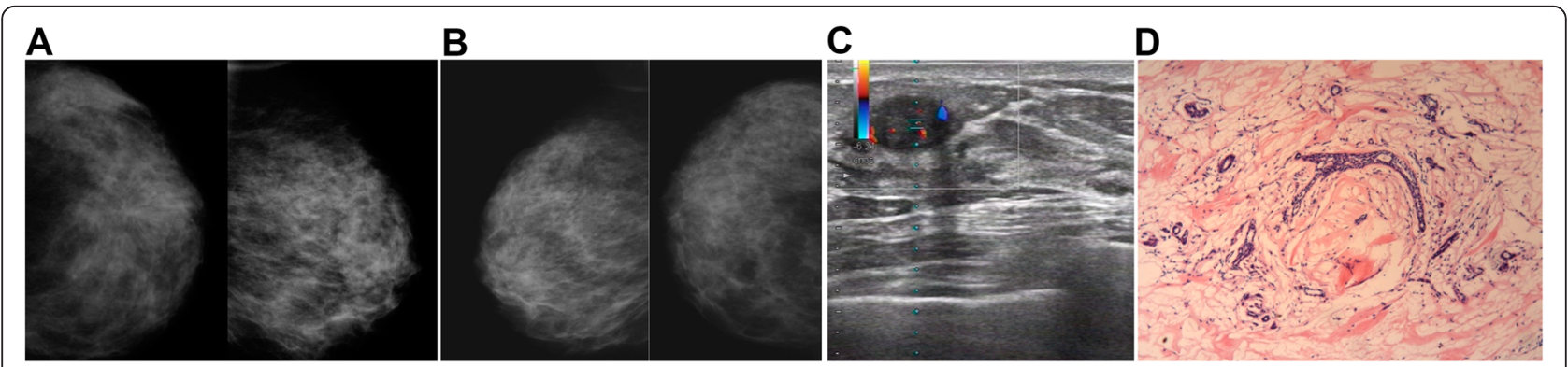

Figure 2 MG, US, and post-surgical pathology results from a 46-year-old patient with a lump in her left breast. (A) MG of the left breast could not identify the location of the lesions. (B) MG of the right breast of the same patient. (C) US showed an oval mass in her left breast. (D) Post-surgical pathological examination revealed adenosis of the left breast complicated by fibroadenoma (HE staining, $\times 100)$. This represents a typical example of misdiagnosed lesion sites by MG compared with pathological examination. 


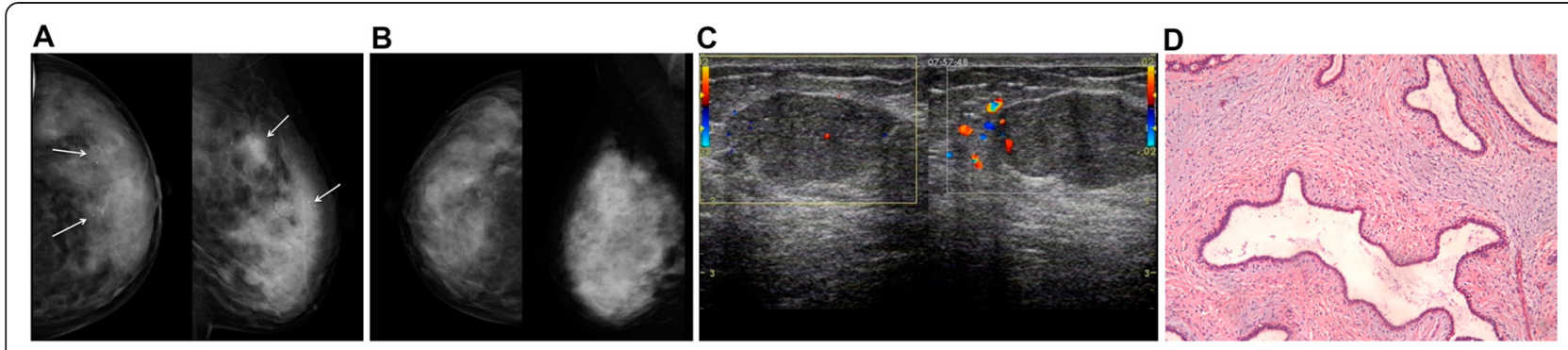

Figure 3 MG, US, and post-surgical pathology results from a 38-year-old patient with a lump in her left breast. (A) Craniocaudal and mediolateral oblique MG of the left breast displayed lesions in the left outer breast, with multiple clusters of microcalcifications, unclear lesion boundaries (white arrows), and unknown lesion sizes. (B) MG of the right breast of the same patient. (C) The size of lesion was $3 \mathrm{~cm}$ by US. (D) Post-surgical pathological examination revealed adenosis of the breast complicated by fibroadenoma, with focal calcifications (HE staining, $\times 100$ ). This represents a typical example of the inability of MG to correctly determine the lesion boundaries and size compared with pathological examination.

diagnostic accuracy of MG. Indeed, dense breast tissues interfere with the interpretation of MG [5,20-23].

In addition, MG could not exactly determine the size and location of the breast lesion in many cases. This method only achieved a low agreement rate with surgery for detecting the lesion size and location. A potential reason is that the surrounding tissues and the lesions have similar X-ray attenuation, covering the shape and size of the mass. Therefore, some small cancers may be missed, and some benign lesions may be subjected to an unnecessary surgery. Nevertheless, MG showed good sensitivity for large palpable lesions, but these lesions would undergo surgery anyway.

Compared with MG, dense breast tissues are hyperechoic on US and most lesions are hypoechoic $[24,25]$. Therefore, because US are not affected by high density breast tissues, breast US has a higher sensitivity for detecting breast cancers in women with dense breast tissue [26-28]. Therefore, since Chinese women often have dense breasts, US should be more effective, accurate, and useful as the breast imaging tools. In addition, women are not exposed to radiations.

In the present study, the results strongly suggest that US was significantly better than MG for detecting breast diseases. There was no BI-RADS category 0 case reported by US. In young women and women with dense breasts, US appears superior to MG as an effective diagnostic tool in the evaluation of breast diseases. US had a significantly greater diagnostic accuracy than MG. Finally, US had a high agreement rate with surgery and it could be used to determine the exact size and location of the breast lesions. Therefore, US could be a better screening modality than MG in Chinese women. In addition, it is much cheaper than other modalities such as MRI, making it the modality of choice for areas with a poor economic status. MRI's sensitivity to invasive cancers is nearly $100 \%$ [29-31], and that it is not influenced by age or gland density degree [31,32]. However, MRI is not the best imaging modality to assess microcalcifications detected on MG since MRI is based on changes in the spin of hydrogen protons and that microcalcifications contain few of these [33]. In addition, MRI machines are expensive, as well as the examinations per se. Nevertheless, US should be compared with new modalities such as breast tomosynthesis [34,35]. In some centers, MG and US could be used together to maximize the detection of breast cancer [36]. In young asymptomatic high-risk women ( $<50$ years old), digital MG could be used as the primary screening modality, and US could be performed if necessary [37]. These results could be generalized to all women with dense breasts, not only Chinese ones.

The present study is not without limitations. In addition to its retrospective nature, the sample size was small and was from a single center. Multicenter studies should be performed to confirm these results.

\section{Conclusions}

In conclusion, US was better than MG in the preoperative evaluation of breast diseases of Chinese women. These results suggest that US could be more useful for detecting breast lesions in China.

\section{Abbreviations}

MG: mammography; MRI: magnetic resonance imaging.

\section{Competing interests}

The authors declare that they have no competing interests.

\section{Authors' contributions}

$\mathrm{HZ}$ carried out the studies, participated in the sequence alignment, and drafted the manuscript; LWZ participated in the design of the study and performed the statistical analysis; XPG conceived of the study, participated in its design and coordination, and helped to draft the manuscript; and SHZ participated in the sequence alignment. All authors read and approved the final manuscript.

\section{Acknowledgments}

This study was supported by the Anhui Provincial Natural Science Research Project (\#KJ2011Z188). We wish to thank Tang Tong, MD (Department of Breast Surgery of The Second Affiliated Hospital of Anhui Medical University) for the help in data acquisition, Peng Mei, MD (Department of Ultrasonography of The Second Affiliated Hospital of Anhui Medical University) for the help in data analysis and interpretation, and Wu Qiang, PhD (Department of Pathology of The Second Affiliated Hospital of Anhui Medical University) for the help in data acquisition. 


\section{Author details}

'Department of Radiology, The Second Affiliated Hospital of Anhui Medical University, 678 Furong Road, Hefei, Anhui 230000, China. ${ }^{2}$ Department of Surgery, The Second Affiliated Hospital of Anhui Medical University, 678 Furong Road, Hefei, Anhui 230000, China.

Received: 2 September 2014 Accepted: 10 April 2015

Published online: 21 April 2015

\section{References}

1. Brem RF, Rapelyea JA, Zisman G, Hoffmeister JW, Desimio MP. Evaluation of breast cancer with a computer-aided detection system by mammographic appearance and histopathology. Cancer. 2005;104:931-5.

2. Boyd NF, Guo H, Martin LJ, Sun L, Stone J, Fishell E, et al. Mammographic density and the risk and detection of breast cancer. N Engl J Med. 2007;356:227-36

3. Maskarinec G, Meng L, Ursin G. Ethnic differences in mammographic densities. Int J Epidemiol. 2001;30:959-65.

4. Pisano ED, Gatsonis C, Hendrick E, Yaffe M, Baum JK, Acharyya S, et al. Diagnostic performance of digital versus film mammography for breast-cancer screening. N Engl J Med. 2005;353:1773-83.

5. Shao H, Li B, Zhang X, Xiong Z, Liu Y, Tang G. Comparison of the diagnostic efficiency for breast cancer in Chinese women using mammography, ultrasound, MRI, and different combinations of these imaging modalities. J Xray Sci Technol. 2013;21:283-92.

6. Bassett LW, Berg WA. Breast Imaging Reporting and Data System, BI-RADS: mammography. 4th ed. Reston: American College of Radiology; 2003.

7. Kalbhen CL, Kezdi-Rogus PC. Changes in breast compressibility with age: implications for stereotactic biopsy. Can Assoc Radiol J. 1999;50:93-7.

8. Kayar R, Civelek S, Cobanoglu M, Gungor O, Catal H, Emiroglu M. Five methods of breast volume measurement: a comparative study of measurements of specimen volume in 30 mastectomy cases. Breast Cancer (Auckl). 2011:5:43-52

9. Miller AB, To T, Baines CJ, Wall C. The Canadian National Breast Screening Study: update on breast cancer mortality. J Natl Cancer Inst Monogr. 1997;1997:37-41

10. Miller AB, Wall C, Baines CJ, Sun P, To T, Narod SA. Twenty five year follow-up for breast cancer incidence and mortality of the Canadian National Breast Screening Study: randomised screening trial. BMJ. 2014;348:9366.

11. Roberts MM, Alexander FE, Anderson TJ, Chetty U, Donnan PT, Forrest P, et al. Edinburgh trial of screening for breast cancer: mortality at seven years. Lancet. 1990:335:241-6.

12. Liu J, Liu PF, Li JN, Qing C, Ji Y, Hao XS, et al. Analysis of mammographic breast density in a group of screening chinese women and breast cancer patients. Asian Pac J Cancer Prev. 2014;15:6411-4.

13. Kerlikowske K, Grady D, Barclay J, Sickles EA, Ernster V. Effect of age, breast density, and family history on the sensitivity of first screening mammography. JAMA. 1996;276:33-8.

14. Gierach GL, Ichikawa L, Kerlikowske K, Brinton LA, Farhat GN, Vacek PM, et al. Relationship between mammographic density and breast cancer death in the Breast Cancer Surveillance Consortium. J Natl Cancer Inst. 2012;104:1218-27.

15. Suzuki A, Ishida T, Ohuchi N. Controversies in breast cancer screening for women aged 40-49 years. Jpn J Clin Oncol. 2014;44:613-8.

16. Wang FL, Chen F, Yin H, Xu N, Wu XX, Ma JJ, et al. Effects of age, breast density and volume on breast cancer diagnosis: a retrospective comparison of sensitivity of mammography and ultrasonography in China's rural areas. Asian Pac J Cancer Prev. 2013;14:2277-82.

17. Hooley RJ, Greenberg KL, Stackhouse RM, Geisel JL, Butler RS, Philpotts LE. Screening US in patients with mammographically dense breasts: initial experience with Connecticut Public Act 09-41. Radiology. 2012;265:59-69.

18. Weigert J, Steenbergen S. The connecticut experiment: the role of ultrasound in the screening of women with dense breasts. Breast J. 2012;18:517-22.

19. Tsai HW, Twu NF, Ko CC, Yen MS, Yang MJ, Chao KC, et al. Compliance with screening mammography and breast sonography of young Asian women. Eur J Obstet Gynecol Reprod Biol. 2011;157:89-93.

20. Zanello PA, Robim AF, Oliveira TM, Elias Junior J, Andrade JM, Monteiro CR, et al. Breast ultrasound diagnostic performance and outcomes for mass lesions using Breast Imaging Reporting and Data System category 0 mammogram. Clinics (Sao Paulo). 2011;66:443-8.
21. Cherel P, Hagay C, Benaim B, De Maulmont C, Engerand S, Langer A, et al. Mammographic evaluation of dense breasts: techniques and limits. J Radiol. 2008:89:1156-68

22. Devolli-Disha E, Manxhuka-Kerliu S, Ymeri H, Kutllovci A. Comparative accuracy of mammography and ultrasound in women with breast symptoms according to age and breast density. Bosn J Basic Med Sci. 2009;9:131-6.

23. Liberman $\mathrm{L}$, Menell JH. Breast imaging reporting and data system (BI-RADS). Radiol Clin North Am. 2002;40:409-30.

24. Crystal P, Strano SD, Shcharynski S, Koretz MJ. Using sonography to screen women with mammographically dense breasts. AJR Am J Roentgenol. 2003;181:177-82.

25. Zhi H, Ou B, Luo BM, Feng X, Wen YL, Yang HY. Comparison of ultrasound elastography, mammography, and sonography in the diagnosis of solid breast lesions. J Ultrasound Med. 2007;26:807-15.

26. Jiang $H, B u X$, Sun $Y, X u K$, Zheng $X$. Ultrasonography is more accurate than mammography in preoperative evaluations of palpable breast tumors in Chinese women. Breast J. 2013;19:677-9.

27. Leong LC, Gogna A, Pant R, Ng FC, Sim LS. Supplementary breast ultrasound screening in Asian women with negative but dense mammograms-a pilot study. Ann Acad Med Singapore. 2012;41:432-9.

28. Masroor I, Ahmed MN, Pasha S. To evaluate the role of sonography as an adjunct to mammography in women with dense breasts. J Pak Med Assoc. 2009:59:298-301.

29. Orel SG. High-resolution MR, imaging for the detection, diagnosis, and staging of breast cancer. Radiographics. 1998;18:903-12.

30. Kelcz F, Santyr G. Gadolinium-enhanced breast MRI. Crit Rev Diagn Imaging. 1995:36:287-338

31. Van Goethem M, Tjalma W, Schelfout K, Verslegers I, Biltjes I, Parizel P. Magnetic resonance imaging in breast cancer. Eur J Surg Oncol. 2006:32:901-10

32. Lehman CD, Isaacs C, Schnall MD, Pisano ED, Ascher SM, Weatherall PT, et al. Cancer yield of mammography, MR, and US in high-risk women: prospective multi-institution breast cancer screening study. Radiology. 2007;244:381-8.

33. Bazzocchi M, Zuiani C, Panizza P, Del Frate C, Soldano F, Isola M, et al. Contrast-enhanced breast MRI in patients with suspicious microcalcifications on mammography: results of a multicenter trial. AJR Am J Roentgenol. 2006;186:1723-32

34. Gur D. Tomosynthesis-based imaging of the breast. Acad Radiol. 2011;18:1203-4.

35. Zuley ML, Bandos Al, Ganott MA, Sumkin JH, Kelly AE, Catullo VJ, et al. Digital breast tomosynthesis versus supplemental diagnostic mammographic views for evaluation of noncalcified breast lesions. Radiology. 2013;266:89-95.

36. Chae EY, Kim HH, Cha JH, Shin HJ, Kim H. Evaluation of screening whole-breast sonography as a supplemental tool in conjunction with mammography in women with dense breasts. J Ultrasound Med. 2013;32:1573-8.

37. Fletcher SW, Black W, Harris R, Rimer BK, Shapiro S. Report of the International Workshop on Screening for Breast Cancer. J Natl Cancer Inst. 1993:85:1644-56.

\section{Submit your next manuscript to BioMed Central and take full advantage of:}

- Convenient online submission

- Thorough peer review

- No space constraints or color figure charges

- Immediate publication on acceptance

- Inclusion in PubMed, CAS, Scopus and Google Scholar

- Research which is freely available for redistribution 